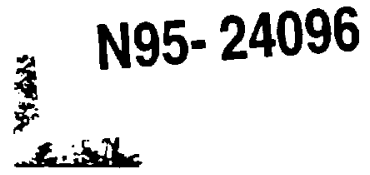

\title{
Measuring Forest Landscape Patterns in the Cascade Range of Oregon, USA
}

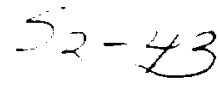

\author{
William J. Ripple
}

Environmental Remote Sensing Applications Laboratory, Department of Forest Resources. Oregon State University, Corvallis, Oregon 97331, USA

\section{G. A. Bradshaw}

Environmental Remote Sensing Applications Laboratory and Department of Forest Science, Oregon State University, Corvallis, Oregon 97331, USA

$\&$

\section{Thomas A. Spies}

USDA Forest Service, Pacific Northwest Research Station and

Oregon State University, Corvallis, Oregon 97331. USA

(Received 24 April 1990; revised version received and accepted 8 October 1990)

\section{ABSTRACT}

This paper describes the use of a set of spatial statistics 10 quantify the landscape pattern caused by the patchwork of clearcuts made over a 15-vear period in the western Cascades of Oregon. Fifteen areas were selected at random to represent a diversity of landscape fragmentation patterns. Managed forest stands (patches) were digitized and analysed to produce both tabular and mapped information describing patch size, shape, abundance and spacing. and matrix characteristics of a given area. In addition. a GIS fragmentation index was developed which was found to be sensitive to patch abundance and to the spatial distribution of patches. Use of the GIS-derived index provides an automated method of determining the level of forest fragmentation and can be used to facilitate spatial analysis of the landscape for later coordination with field and remotely sensed data. A comparison of the spatial statistics calculated for the swo years indicates an increase in forest fragmentation as characterized by an increase in mean patch abundance and $a$ decrease in interpatch distance, amount of interior natural forest habitat, and

73

Biol. Conserv. 0006-3207/91/\$03.50 (C) 1991 Elsevier Science Publishers Ltd, England. Printed in Great Britain 
the GIS fragmentation index. Such statistics capable of quantifying patch shape and spatial distribution may prove important in the evaluation of the changing character of interior and edge habitats for wildlife.

\section{INTRODUCTION}

The Douglas-fir Pseudotsuga menziesii (Mirb.) Franco forests of western Oregon have been cut extensively during the past 40 years. In these forests, clearcuts, new plantations, and second-growth stands now exist on the landscape formerly dominated by extensive old-growth forests and younger forests resulting from fire disturbance (Spies \& Franklin, 1988). Consequently, the landscape has become more spatially heterogeneous. Some of the effects of this newly created landscape on the forest ecosystem are immediately apparent. For example, the amount of old-growth forest habitat for interior species such as the northern spotted owl Strix occidentalis caurina is altered with forest harvesting practices. Less well understood are the long-term and more subtle interactive effects on ecosystem processes (e.g. changes in species diversity and abundance, nutrient cycling and primary forest productivity), which may occur as a result of the changed forest mosaic. It is generally accepted that wildlife ecology and behavior may be strongly dependent on the nature and pattern of landscape elements (Forman \& Godron, 1986), but few precise measurements relating these changes to landscape spatial alteration have been made. Properties of forested landscapes such as patch size, the amount of edge, the distance between habitat areas, and the connectedness of habitat patches have a direct influence on the flora and fauna (Thomas, 1979; Harris, 1984; Franklin \& Forman, 1987; Ripple \& Luther, 1987). For these reasons, models and monitoring schemes are urgently needed for prescribing the location, size, and shape of future harvest units and old-growth habitat patches. With proper design, these forest landscapes should be able to achieve desired habitat values and maintain biological diversity (Noss, 1983; Harris, 1984; Franklin \& Forman, 1987).

As a first step to studying forest landscape pattern, the spatial character of the landscape must be quantified to relate ecological processes to landscape configuration. Numerous methods and indices have been proposed for these purposes (e.g. Forman \& Godron, 1986; Milne, 1988; O'Neill et al., 1988). Landscape pattern can be quantified using statistics in terms of the landscape unit itself (e.g. patch size, shape, abundance, and spacing) as well as the spatial relationship of the patches and matrix comprising the landscape (e.g. nearest-neighbor distance and amount of contiguous matrix). A selection of these measures can therefore describe the several aspects of fragmentation which occur as the result of forest harvesting practices. 
Because spatial analyses are often cumbersome due to large amounts of data, it is desirable that the analysis be automated. Furthermore, it should be amenable for study at various scales in concert with a variety of data types. Automated systems such as geographical information systems (GIS) address such needs (Ripple. 1987, 1989). With the development of GIS, the ability to readily measure spatial characteristics of landscapes in conjunction with field and remotely sensed data has become possible.

The overall goal of the present study was to test the feasibility of measuring forest landscape patterns accurately using a set of spatial statistics and a GIS. Specifically, we set out to apply a set of statistics to a series of forested landscapes in the Cascade Range of western Oregon to (1) assess the sensitivity of these statistics to characterize landscape pattern; (2) develop and test a GIS-derived index to measure fragmentation; and (3) quantify the change and types of forest fragmentation through time in our study area. The results of this pilot study are intended to aid the forester, wildlife biologist, and land manager in assessing change in wildlife habitat and alteration in ecosystem processes as a result of forest fragmentation.

\section{STUDY AREA}

The study area consisted of the Blue River and Sweet Home ranger districts of the Willamette National Forest. According to Franklin and Dyrness (1973), these ranger districts lie primarily in the western hemlock Tsuga heterophylla and pacific silver fir Abies amabilis vegetation zone, with the major forest tree species consisting of Douglas-fir, western hemlock, pacific silver fir, noble fir Abies procera, and western redcedar Thuja plicata. The climate can be characterized as maritime with wet, mild winters and dry, warm summers. Under natural conditions, Douglas-fir is the seral dominant at elevations below $1000 \mathrm{~m}$, where it typically develops nearly pure, evenaged stands after fire. Large areas are covered by old-growth Douglas-fir/ western hemlock forests in which Douglas-firs are over 400 years old. Fires during the past 200 years have created a complex mosaic of relatively evenaged natural stands throughout the study area. Superimposed on this natural mosaic is a second component of pattern complexity resulting from timber harvesting over the last 40 years.

\section{METHODS}

\section{Data acquisition}

Landscapes were classified in terms of managed and natural elements. Managed forest stands (typically young forest plantations of up to 
approximately 40 years old established after clearcutting) were defined as internally homogeneous units (or managed patches) embedded in a matrix consisting of natural, uncut forest. This two-phase mosaic is a simplified representation of a more complex system in which many patch and matrix types exist. For the present analysis, however, we chose to classify the elements of the system as either 'managed' or 'natural'. A managed patch consisted of one, or (if adjacent) more than one, unit that was clearcut in the past.

Maps of forest patterns were constructed for the years 1972 and 1987. Managed forest patches for 1972 were mapped using high-altitude infrared images (scale 1:60000) and were transferred to US Forest Service vegetation maps using a zoom transfer scope. The 1987 data were acquired from vegetation maps produced in 1987 by the Forest Service at a scale of 1:15840 for the entire Willamette National Forest. Fifteen forested landscapes were chosen at random from the Blue River and Sweet Home ranger districts' vegetation maps for this study. Each sample landscape consisted of a rectangle representing approximately $3.5 \times 5.0 \mathrm{~km}(1750 \mathrm{ha})$. To qualify for selection, each landscape was required to be forested, lie within US Forest Service land, and contain at least one managed patch by 1972. Other landscapes were rejected during the random selection process. Several of the selected landscapes included roadless areas with much uncut forest land. The locations, sizes, and shapes within the managed forest patches and the natural forest matrix were digitally recorded as polygons for both the 1972 and 1987 data. The total number of digitized patches for 1972 and 1987 were 150 and 298 , respectively.

\section{Landscape statistics}

The degree of fragmentation sustained by the forest matrix which characterizes a given landscape may be described as a function of the varying size, shape, spatial distribution, and density of clearcut patches (Burgess \& Sharpe, 1981). Thus the degree of fragmentation can be measured in a number of ways. Because a single statistic is usually deemed insufficient to capture the entire spatial character of the landscape, a suite of statistics was selected. Five groups of statistics were used to quantify landscape heterogeneity and pattern for each of the fifteen areas for each of the two years: (1) patch size; (2) patch abundance; (3) patch shape; (4) patch spacing; and (5) matrix characteristics. Patch sizes and shapes were only determined for interior patches (i.e. patches that were not truncated by the borders of the landscape study sites).

Patch size for each year and sample area were expressed in terms of the average patch area and average patch perimeter. The area and perimeter of each patch were computed using the digitizing routine mentioned above. 
The means of the patch areas and perimeters for each landscape for each year were also calculated. The second set of statistics, 'patch abundance', includes a measure of the patch density (expressed as the number of managed forest patches present per landscape study area) and percent in patches (the percent of the total landscape area occupied by managed patches). Means of these two statistics were calculated for each landscape and year. Because patch shape and patch spacing statistics can involve more than one variable in their calculation, some background discussion of the equations is included.

Patch shape was measured in three different ways: (1) the simple ratio of patch perimeter to patch area; (2) the fractal dimension; and (3) a diversity index. All three indices are a function of the perimeter and area of a given patch. The application of these similar measures on the same data set afforded an opportunity to compare their ability to detect spatial pattern.

The fractal dimension, $D$, was used to quantify the complexity of the shape of a patch using a perimeter-area relation. Specifically

$$
P \approx A^{D / 2}
$$

where $P$ is the digitized patch perimeter and $A$ is the patch area (Burrough, 1986). The fractal dimension for each sample area and year was estimated by regressing the logarithm of patch area on its corresponding log-transformed perimeter. The appeal of fractal analysis is that it can be applied to spatial features over a wide variety of scales. A fractal dimension greater than 1 indicates a departure from a euclidean geometry, i.e. an increase in shape complexity. As $D$ approaches 2 , the patch perimeter becomes 'infilling' (Krummel et al., 1987).

A similar index is the diversity index, $D I$, which was used to express patch shape as

$$
D I=\frac{P}{2 \sqrt{\pi A}}
$$

where the variables are defined as above in eqn (1) (Patton, 1975). Theoretically, the diversity index increases to 1 as the unit shape approaches a circle, similar to the case of the fractal dimension. However, in contrast, the diversity index increases without limit as patch shape becomes more complex.

Patch spacing was characterized by measures of the mean nearestneighbor distance and a measure of dispersion. The mean nearest-neighbor distance was calculated manually with a scale by measuring the distance from the centroid of each patch to the centroid of its nearest neighbor and computing the mean distance for the sample landscape. The centroid of each patch was determined through an ocular estimate procedure. Clark and 


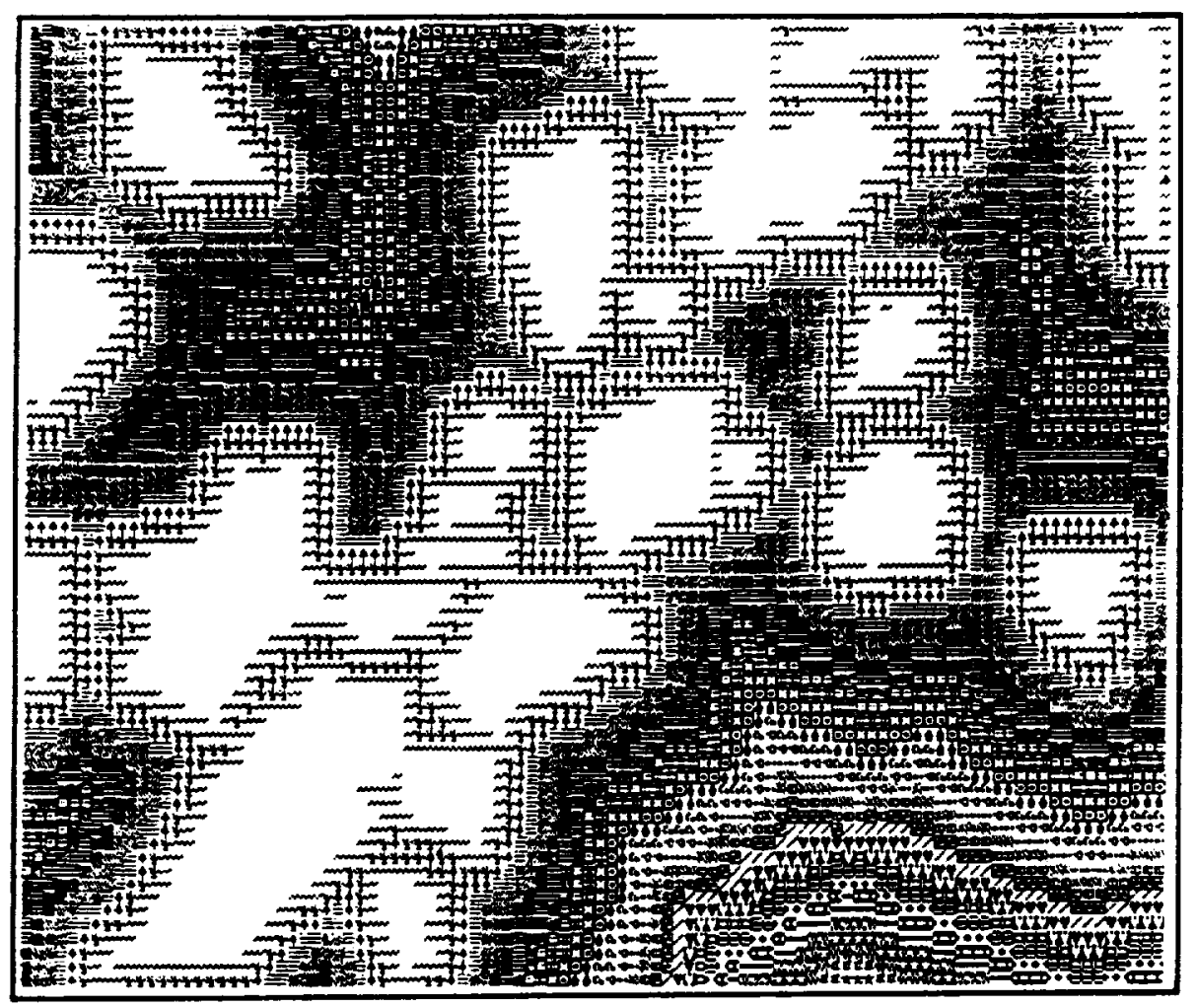

Proximity to Managed Patches

$50 \mathrm{~m}$ Cells

\begin{tabular}{|c|c|c|c|c|c|}
\hline سمس & 0.05 & $\mathrm{Tm}$ & wax & 0.90 & $\mathrm{Km}$ \\
\hline+4 & 0.10 & $\mathrm{Km}$ & $\infty$ & 0.95 & Im \\
\hline +*4 & 0.15 & $\mathbf{x}$ & an & 1.00 & $x m$ \\
\hline$\equiv$ & 0.20 & $x$ & $M$ & 1.05 & $\ln$ \\
\hline $\max$ & 0.25 & $\operatorname{sm}$ & $m$ & 2.20 & m \\
\hline 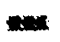 & 0.30 & $\mathrm{xm}$ & (w) & 1.15 & $\mathbf{x}$ \\
\hline & 0.35 & $\mathrm{xm}$ & 0 & 1.20 & $\mathbf{r m}$ \\
\hline$\Longrightarrow$ & 0.40 & $\mathbf{X x}$ & $e a$ & 1.25 & $\mathrm{Km}$ \\
\hline & 0.45 & $\mathrm{Im}$ & $\cdots \cdots$ & 1.30 & $\mathrm{xm}$ \\
\hline$E=3$ & 0.50 & $\ln$ & $x$ & 1.35 & $\mathbf{x m}$ \\
\hline$=$ & 0.55 & $\mathrm{~km}$ & - & 1.40 & $\mathbf{x}$ \\
\hline Ex: & 0.60 & $\mathrm{rm}$ & $\boldsymbol{x} x$ & 1.45 & س \\
\hline$E=0$ & 0.65 & In & 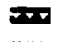 & 1.50 & Im \\
\hline$\bullet$ & 0.70 & $\mathrm{rm}$ & wn: & 1.55 & $\mathrm{xm}$ \\
\hline $\cos x$ & 0.75 & $x$ & $x=2$ & 1.60 & $\mathrm{Km}$ \\
\hline 800 & $\begin{array}{l}0.80 \\
0.85\end{array}$ & $\mathrm{~km}$ & $x+t$ & 1.65 & m \\
\hline
\end{tabular}

Fig. 1. An example of a proximity map using the spread function in the pMAP geographic information system. Cell values in the matrix were assigned based on their distance to the nearest managed forest patch (areas shown in white). The GIS fragmentation index (GISfrag) was determined by calculating the mean of all grid cell values on the proximity map. 
Evans (1954) developed a measure of dispersion of patches using the equation

$$
R=2 \rho^{1 / 2} \bar{\tau}
$$

where $R$ is dispersion, $\bar{r}$ is the mean nearest-neighbor distance, and $\rho$ is the mean patch density (number of patches per unit area; see also Pielou, 1977 , p. 155). Dispersion is a measure of the non-randomness of the patch arrangement. In a random population, $R=1 ; R$ less than 1 indicates aggregation of the patches, while $R$ greater than 1 indicates that the patch population forms a regular dispersed pattern or spacing.

A fifth group of statistics was calculated which predominantly reffects the character of the matrix (in this case, natural forested land) as opposed to managed patch configuration (clearcut areas): namely, a GIS-derived index (christened GISfrag), matrix contiguity, interior habitat, and total patch edge. To determine contiguity, a mylar sheet with an $8 \times 8$ grid consisting of 64 cells each with a size of 27 ha was overlaid on the sample landscape maps. The largest contiguous natural forest area (i.e. the largest number of contiguous grid cells) in the sample landscape was recorded. Using this $8 \times 8$ grid, the contiguity index could potentially range from 0 (a landscape with no natural forest patches greater than 27 ha, i.e. highly fragmented) to 64 (a landscape with no managed stands, and hence no fragmentation). A 27-ha cell size was chosen because it was considered to be a viable habitat patch size and fits within the structure of the existing landscape.

The GIS fragmentation index (GISfrag) was computed by first producing a proximity map using the SPREAD function in the pMAP GIS software (Spatial Information Systems, 1986). This procedure assigned cell values based on the distance to the managed forest patches (i.e. a distance of one cell away from a managed patch was equal to $50 \mathrm{~m}$, a distance of two cells was equal to $100 \mathrm{~m}$, and so forth; see Fig. 1 for an example of a digital map illustrating all matrix distances to managed patches). A GISfrag was computed as the mean value of all the grid cell values on the proximity map, including the managed patches which were assigned values of zero. Large mean values reflected a low degree of forest fragmentation while maximum fragmentation occurred when the mean values approach zero.

The spread function in pMAP was also used to calculate the amount of interior forest habitat. Interior forest was defined as the amount of natural forest remaining after removing an edge zone of $100 \mathrm{~m}$ (approximately two tree heights) into the natural forest matrix (Fig. 2). The mean total edge was simply the average of the total managed patch edges for each landscape. A non-parametric test (Wilcoxon rank sum) for the difference between mean values was performed for each landscape and year for each of the variables listed above to assess the ability of these variables to reflect landscape change. 


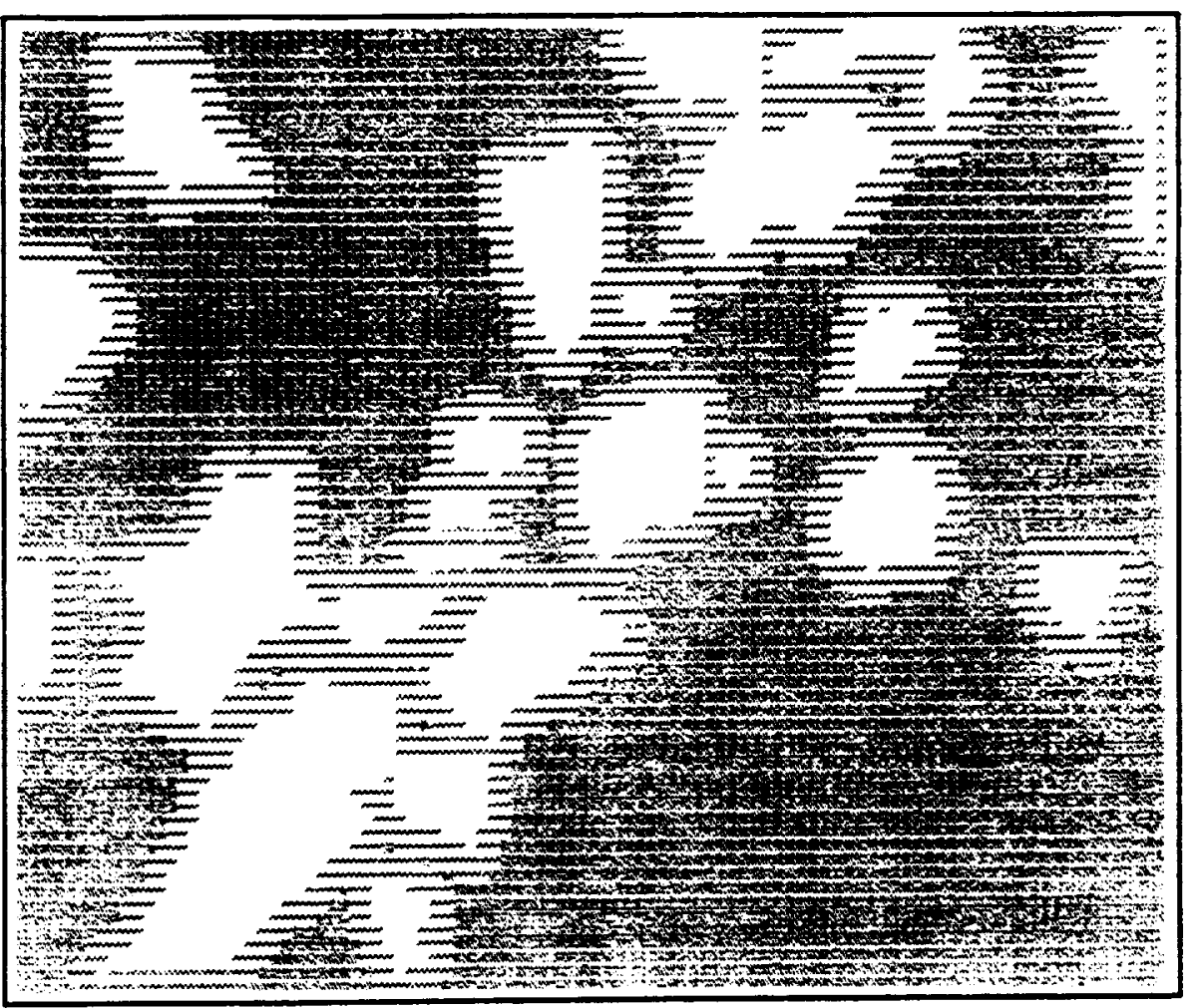

\section{Interior Forest Habitat $50 \mathrm{~m}$ Cells}

$\begin{array}{ccc}\text { Label } & \text { Percent } \\ \text { Interior Habitat } & 57.73 \\ & \text { Edge Effect }(100 \mathrm{~m}) & 21.87 \\ & \text { Managed Forest } & 20.40\end{array}$

Fig. 2. An example of an interior forest habitat map generated by pMAP. The interior forest habitat is defined here as the amount of natural forest remaining after removing an edge zone of $100 \mathrm{~m}$ into the natural forest. 


\section{RESULTS AND DISCUSSION}

\section{Landscape structure}

The degree of forest fragmentation as measured by the statistics discussed above increased significantly over the 15 years spanning 1972 to 1987 (Table 1 and Fig. 3). Overall, patch area and patch perimeter decreased by $17 \%$ and

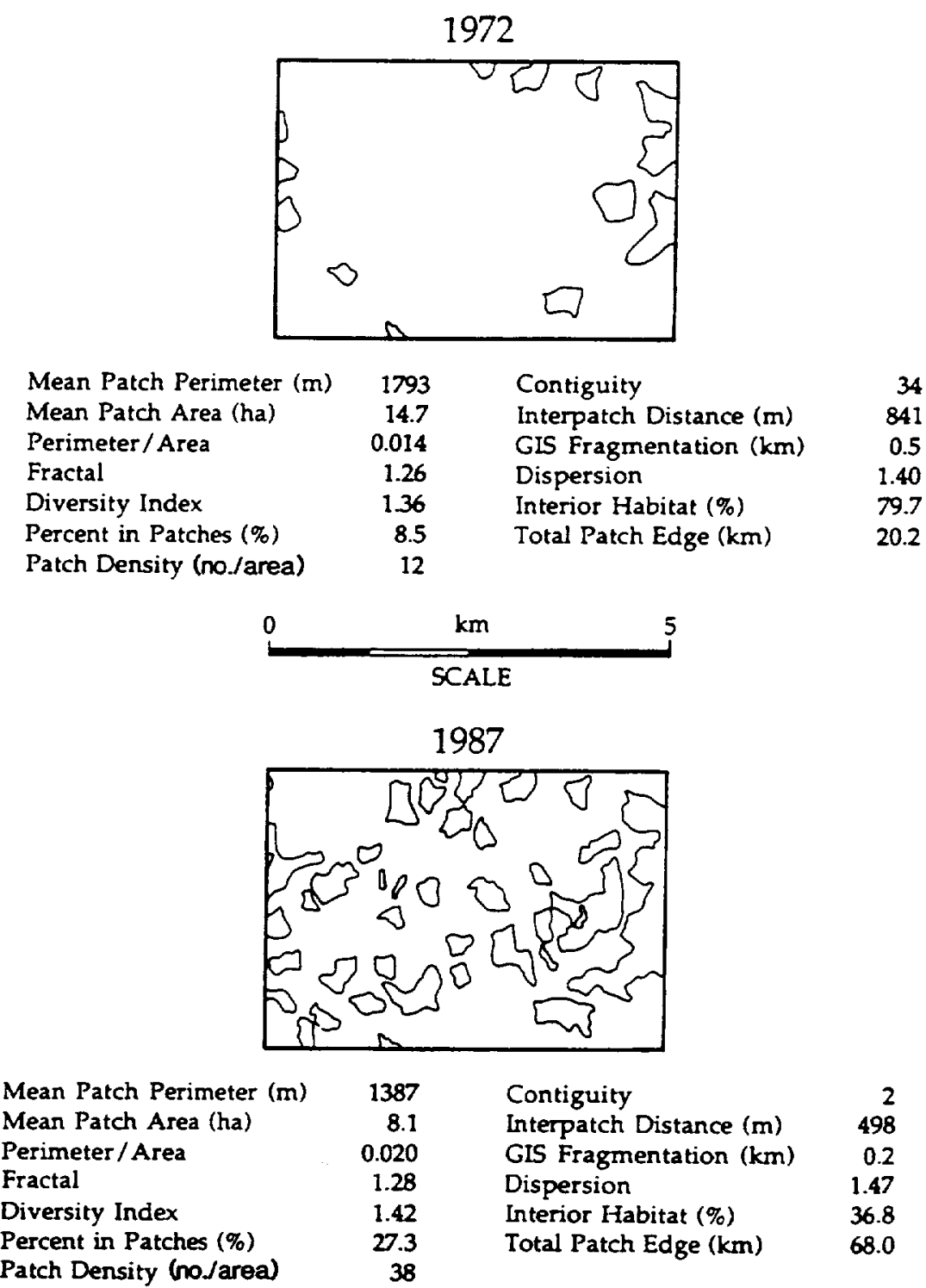

Fig. 3. A graphical and statistical illustration of landscape change between the years 1972 and 1987 for one of the landscapes used in the study. 
TABLE 1

Descriptive Statistics for 1972 and 1987 Landscapes

\begin{tabular}{|c|c|c|c|c|c|}
\hline Variable & Mean & $\begin{array}{l}\text { Standard } \\
\text { deviation }\end{array}$ & Minimum & Maximum & $\mathrm{p}$ value \\
\hline \multicolumn{6}{|l|}{ Managed paich size } \\
\hline $\begin{array}{l}\text { Mean patch perimeter (m) } \\
1972\end{array}$ & 2075 & 512 & 1599 & 3492 & \\
\hline $\begin{array}{l}\text { Mean paich perimeter }(\mathrm{m}) \\
\quad 1987\end{array}$ & 1848 & 452 & 1211 & 2797 & 0.096 \\
\hline Mean patch area (ha) 1972 & $19 \cdot 5$ & $9 \cdot 1$ & $1 \cdot 7$ & $42 \cdot 7$ & \\
\hline Mean patch area (ha) 1987 & $16 \cdot 2$ & $8-3$ & $6 \cdot 6$ & 38.5 & 0.027 \\
\hline \multicolumn{6}{|l|}{ Managed patch shape } \\
\hline Perimeteriarea 1972 & 0.013 & 0.0037 & 0.007 & 0.022 & \\
\hline Perimeter/area 1987 & 0.018 & 0.0053 & 0.007 & 0.028 & 0.027 \\
\hline Fractal 1972 & $1 \cdot 26$ & 0.02 & $1 \cdot 24$ & $1 \cdot 28$ & \\
\hline Fractal 1987 & $1 \cdot 27$ & 0.02 & $1 \cdot 24$ & $1 \cdot 32$ & 0.023 \\
\hline Diversity index 1972 & $1 \cdot 38$ & 0.11 & $1 \cdot 22$ & 1.53 & \\
\hline Diversity index 1987 & $1 \cdot 40$ & 0.09 & $1 \cdot 23$ & 1.52 & 0.027 \\
\hline \multicolumn{6}{|l|}{ Managed patch abundance } \\
\hline Percent in patches 1972 & $9 \cdot 5$ & 7.0 & $1 \cdot 3$ & $27 \cdot 3$ & \\
\hline Percent in patches 1987 & $18 \cdot 2$ & $9 \cdot 6$ & $1 \cdot 3$ & $38 \cdot 1$ & 0.001 \\
\hline $\begin{array}{l}\text { Patch density (no./area) } \\
1972\end{array}$ & $10 \cdot 3$ & $8 \cdot 2$ & 2 & 28 & \\
\hline $\begin{array}{l}\text { Patch densily (no./area) } \\
1987\end{array}$ & $19 \cdot 6$ & 9.7 & 2 & 38 & $0-001$ \\
\hline \multicolumn{6}{|l|}{ Managed patch spacing } \\
\hline $\begin{array}{l}\text { Nearest-neighbor distance (m) } \\
1972\end{array}$ & 928 & 251 & 589 & 1375 & \\
\hline $\begin{array}{l}\text { Nearesi-neighbor distance }(m) \\
\quad 1987\end{array}$ & 661 & 247 & 454 & 1375 & 0.001 \\
\hline Dispersion 1972 & $1 \cdot 22$ & 0.27 & 0.79 & 1.66 & \\
\hline Dispersion 1987 & $1 \cdot 24$ & 0.23 & 0.79 & $1 \cdot 60$ & 1.000 \\
\hline \multicolumn{6}{|l|}{ Matrix characteristics } \\
\hline $\begin{array}{l}\text { GIS fragmentation }(\mathrm{km}) \\
\quad 1972\end{array}$ & 0.8 & 0.5 & 0.1 & $1 \cdot 8$ & \\
\hline $\begin{array}{l}\text { GIS fragmentation }(\mathrm{km}) \\
1987\end{array}$ & 0.5 & 0.5 & 0.1 & 1.8 & 0.003 \\
\hline Matrix contiguity 1972 & $36 \cdot 6$ & $19 \cdot 9$ & 1 & 59 & \\
\hline Matrix contiguity 1987 & $20-6$ & $19 \cdot 1$ & 1 & 59 & 0.003 \\
\hline Interior habitat $(\%) 1972$ & $78 \cdot 2$ & $16 \cdot 1$ & $38 \cdot 4$ & 96.9 & \\
\hline Interior habitat (\%) 1987 & $60 \cdot 2$ & $19 \cdot 7$ & $25 \cdot 6$ & 96.9 & 0.001 \\
\hline Total patch edge $(\mathrm{km}) 1972$ & $19 \cdot 9$ & $15 \cdot 6$ & $2 \cdot 8$ & 59.5 & \\
\hline Total patch edge $(\mathrm{km}) 1987$ & $38 \cdot 4$ & $19 \cdot 8$ & $2 \cdot 8$ & $71 \cdot 6$ & 0.001 \\
\hline
\end{tabular}

These statistics were calculated using patch and matrix variables of the fifteen landscapes to investigate the change in forest fragmentation over time. A non-parametric means test (Wilcoxon rank sum) was performed to evaluate the statistical significance of the differences in the means (see $p$ values). 
$11 \%$ or from 19.5 to 16.2 ha and 2075 to $1848 \mathrm{~m}$, respectively. Although some 1972 patches 'grew' by 1987 as a result of the coalescence of two or more managed patches, individual managed patch size on the whole decreased.

The fractal dimension, the perimeter-to-area ratio, and diversity index indicate a statistically significant increase in patch complexity over time. A contributing factor to this increased complexity may be attributed to the linking of several smaller managed patches which often produces an irregularly shaped patch. The fractal dimension and diversity index appear to be fairly robust measures of an 'average' patch shape and may be capable of discerning subtle changes in patch configuration which are difficult to assess by visual inspection alone. In contrast, because it is not scaleinvariant, the perimeter-to-area ratio must be interpreted carefully.

Patch density increased over the 15 years by $98 \%$. The percent of the landscape in managed patches nearly doubled in the 15-year period from $9.5 \%$ to $18.2 \%$. The mean of the index of contiguity decreased by $44 \%$ by 1987 , reflecting the increased number of clearcuts made in the area. Not surprisingly, the mean nearest-neighbor distance also decreased significantly from 928 to $661 \mathrm{~m}$. Dispersion, however, did not register the change in spatial distribution of patches over time. There was no difference in dispersion from 1972 to 1987 (1.22 versus 1.24), which represents a regular, dispersed spacing pattern for both dates. Since dispersion is a function of

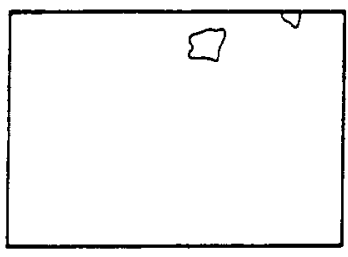

$1.8 \mathrm{~km}$ (36 cells)

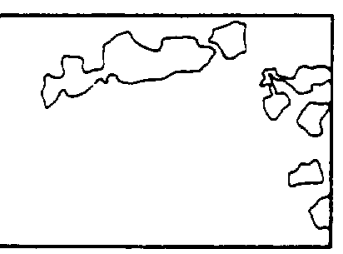

$0.7 \mathrm{~km}$ (14 cells)

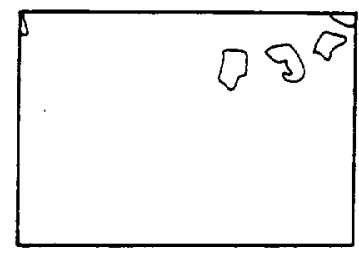

$1.4 \mathrm{~km}(28$ cells)

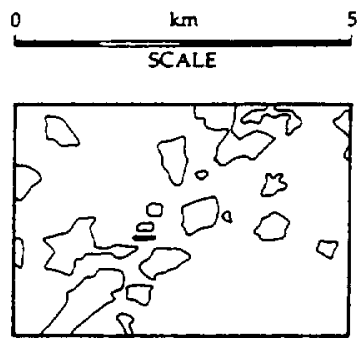

$0.3 \mathrm{~km}(6$ cells)

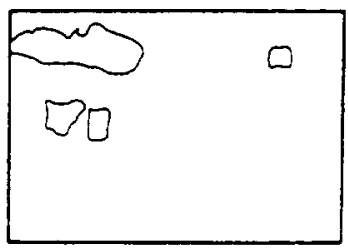

$0.9 \mathrm{~km}$ (19 cells)

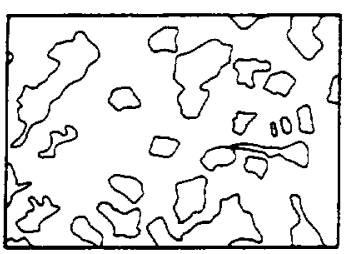

$0.1 \mathrm{~km}(2$ cells)

Fig. 4. The GIS fragmentation index (GISfrag) for a progression of landscape fragmentation levels. Low levels of GISfrag reflect high amounts of forest fragmentation in terms of number of clearcut patches and amount of patch aggregation. This figure consists of six different landscapes and does not represent the same landscape over time. 
both patch density and interpatch distance, we expected it to change because these other variables were statistically different over time. However, the mean change in these two variables was in opposite directions, i.e. patch density increased while nearest-neighbor distance decreased. We conclude that their combined effects canceled one another. The amount of interior forest habitat decreased from $78.2 \%$ in 1972 to $60.2 \%$ in 1987 . This decrease in interior habitat ( $18 \%$ loss) was approximately twice the areal increase in managed patches $(8 \cdot 7 \%)$.

The GISfrag mean decreased by $0.3 \mathrm{~km}$ in 1987 , indicating an increase in forest fragmentation (Table 1). Figure 4 shows the GISfrag for a progression of landscape fragmentation levels. The GISfrag seems to be sensitive to the abundance of patches and the amount of unfragmented contiguous natural forest. Figure 5 demonstrates the influence of patch spacing and the amount of contiguous natural forest on the GISfrag by showing the GISfrag for a pair of landscapes that had the same patch density but a different level of patch aggregation. It should be noted that the GISfrag is only comparable among study areas that are the same size and shape, because the truncation of the matrix as it intersects the study area boundary may influence the value of this index.
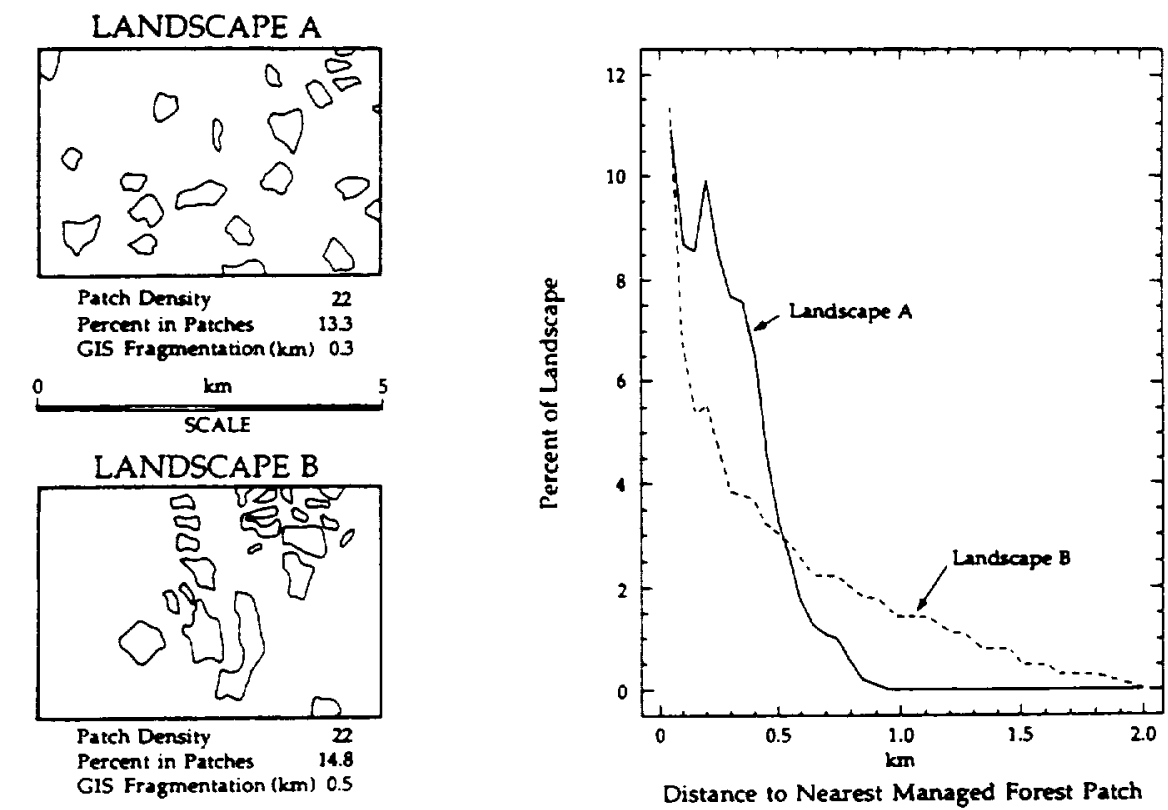

Fig. 5. An example of two landscapes (A and B) having the same patch density (22) but differing level of patch aggregation reflected by correspondingly different GIS fragmentation indices. The accompanying figure to $\mathrm{A}$ and $\mathrm{B}$ is a graph of percent of each landscape versus distance of each point in the landscape to a clearcut (managed) forest patch. The B profile shows more of the landscape with greater distances to the nearest managed patch than $A$. 


\section{Ecological and management implications}

An examination of the results reveals the varying ability of each analysis to describe change in patch and matrix characteristics. The nature and amount of change detected by these different landscape statistics have significance to the ecology and management of forest landscapes. Changes that were evident in patch-level characteristics indicate a trend toward smaller units and a slight trend toward more irregular units. These changes may reflect the increased cutting on steeper, more irregular terrain, more careful 'fitting' of the cutting units as the available cutting area decreased, an effort to optimize big game habitat by increasing the number of cuts, and/or an effort to reduce the visual impact of clearcutting.

The increase in the number of young, managed stand patches and the total amount of edge has implications for habitat potential of the landscapes. Although conclusive information on the effect of edges on vertebrates in western coniferous forest landscapes is not yet available, an increase in edge can benefit some species but prove detrimental to others (Yahner, 1988). For example, it has been observed that big game animals show an affinity for edges (Brown, 1985) and that some bird species occur more frequently on edges than in forest interiors (Rosenberg \& Raphael, 1986). The fact that edge density increased in the present study areas over the past 15 years suggests that the habitat potential has increased for such species as elk, which can successfully utilize the edge environment. The increased dispersal of small clearcuts into the matrix of forest cover provides a corresponding increase in the amount of hiding cover close to forage areas used by the elk (Brown, 1985).

Conversely, a number of other vertebrate species, such as the northern spotted owl, Townsend's warbler Dendroica townsendi, and pileated woodpecker Dryocopus pileatus, may avoid edges (Bull, 1975; Brown, 1985; Rosenberg \& Raphael, 1986). The increase in edge density indicates that habitat conditions for such species favoring interior forest have probably declined markedly. Specifically, the decrease in the mean distance of matrix to managed patch (as measured by GISfrag) and interior forest area are evidence of the decline in interior species habitat conditions. The manner and degree to which the decline affects interior species populations in the study areas are difficult to assess. Although Rosenberg and Raphael (1986) did not find a strong response of vertebrate communities in northern Californian landscapes which sustained a mean percent clearcut of $18 \%$ (roughly the same as the present study), the authors warned that the fragmentation in the region is a relatively recent phenomenon. Long-term vertebrate responses were not yet discernible.

The continued use of dispersed clearcutting increases fragmentation of 
forest landscapes at a rate more rapid than the rate of cutting on a per area basis. Given that the present cutting patterns are decreasing potential interior habitat at a rapid rate, alternative cutting patterns should be considered to reduce the loss of interior habitat and retain the area of large forested patches. Alternative models which aggregate cutting (Franklin \& Forman, 1987) are available and may not require altering current standards and guidelines.

\section{CONCLUSIONS}

In an attempt to describe forest fragmentation, five groups of statistics were employed: patch abundance, patch shape, patch size, patch spacing, and matrix characteristics. By comparing two sets of data representing two dates over a 15-year period, we found that patch abundance, patch spacing measures, and matrix characteristics were most useful in capturing the amount of forest fragmentation over time. Patch size and shape statistics contribute information on specific characteristics of the individual patches and may be useful for applications designed to study specific interior and edge habitats or for the prescription of new clearcuts. In addition, a GIS fragmentation index was developed which proved sensitive to both the quantity and spacing of patches. The GIS provides an automated method of quantifying forest fragmentation to aid in forest and wildlife management decisions, and a means by which field and image data may be used in concert.

Current concerns over forest fragmentation are typically related to a landscape condition in which forest islands occur in a matrix of managed forest plantations. This study suggests that on many Forest Service lands in the Cascade Range this condition is not yet realized, in contrast to many privately owned landscapes in the Cascades in which the matrix is the harvested area and the patches are the natural forest. Consequently, in characterizing fragmentation in some landscapes, characteristics of the matrix (the unmanaged forest) may be of more interest than characteristics of the patches (the managed plantations). Where the matrix is of interest, the interior area, the total edge, and the mean distance to the nearest managed patch (GISfrag) will be the useful descriptors of fragmentation. Additional research is needed to document and substantiate the relationship between forest landscape pattern and the subsequent wildlife/ecosystem response.

\section{ACKNOWLEDGEMENTS}

This project was funded in part by NASA grant number NAGW-1460. The authors would like to thank Robert Gaglioso for assisting in the patch 
mapping and digitization, and Miles Hemstrom, E. Charles Meslow and David $H$. Johnson for providing valuable suggestions on an earlier version of the manuscript.

\section{REFERENCES}

Brown, E. R. (1985). Management of Wildlife and Fish Habitats in Forests of Western Oregon and Washington. US Forest Service, Pacific Northwest Region. Portland, Oregon.

Bult, E. L. (1975). Habitat utilization of the pileated woodpecker, Blue Mountains. Oregon. MS thesis, Oregon State University.

Burgess, R. L. \& Sharpe, D. M. (eds) (1981). Forest Island Dinamics in Mandominated Landscapes. Springer-Verlag, New York.

Burrough, P. A. (1986). Principles of geographic information systems for land resources assessment. Monographs on Soil and Resources Surte1, No.12. Oxford University Press, Oxford.

Clark, P. J. \& Evans. F. C. (1954). Distance to nearest neighbor as a measure of spatial relationships in populations. Ecology, 35, 445-53.

Forman, R. T. T. \& Godron, M. (1986). Landscape Ecology. John Wiley, Chichester.

Franklin, J. F. \& Dyrness, C. T. (1973). Natural Vegeration of Oregon and Washingron. Oregon State University Press, Oregon.

Franklin, J. F. \& Forman, R. T. T. (1987). Creating landscape patterns by cutting: ecological consequences and principles. Landscape Ecol., 1, 5-18.

Harris, L. D. (1984). The Fragmented Forest. University of Chicago Press, Chicago.

Krummel, J. R., Gardner, R. H., Sugihara, G., O'Neill, R. V. \& Coleman, P. R. (1987). Landscape patterns in a disturbed environment. Oikos, 48, 321-4.

Milne, B. T. (1988). Measuring the fractal geometry of landscapes. Appl. Math. Comput., 27, 67-79.

Noss, R. F. (1983). A regional landscape approach to maintain diversity. BioScience, 3, 700-6.

O’Neill, R. V., Krummel, J. R., Gardner, R. H., Sugihara, G., Jackson, B., DeAngelis, D. L., Milne, B. T., Turner, M. G., Zygmunt, B., Christensen, S. W., Dale. V. H. \& Graham, R. L. (1988). Indices of landscape pattern. Landscape Ecol.., 1. 153-62.

Patton, D. R. (1975). A diversity index for quantifying habitat 'edge'. Wildl. Soc. Bull., 3, 171-3.

Pielou, E. C. (1977). Mathematical Ecology. Wiley, New York.

Ripple, W. J. (ed.) (1987). Geographic Information Svstems for Resource Management: A Compendium. American Society for Photogrammetry and Remote Sensing, Bethesda, Maryland.

Ripple, W. J. (ed.) (1989). Fundamentals of Geographic Information Systems: A Compendium. American Society for Photogrammetry and Remote Sensing, Bethesda, Maryland.

Ripple, W. J. \& Luther, T. (1987). The Use of Digital Landsat Data for Wildlife Management on the Warm Springs Indian Reservation of Oregon. Proc. Ann. Convention Amer. Soc. Photogramm. \& Remote Sensing, Baltimore, Maryland. pp. 266-74.

Rosenberg, K. V. \& Raphael, M. G. (1986). Effects of forest fragmentation on 
vertebrates in Douglas-fir forests. In Wildlife 2000, ed. J. Verner. M. L. Morrison \& C. J. Ralph. University of Wisconsin Press, Madison, Wisconsin, pp. 263-72.

Spatial Information Systems (1986). pMAP: A Sofiuare Sistem for Analysis of Spatial Information. Omaha, Nebraska.

Spies. T. A. \& Franklin, J. F. (1988). Old growth and forest dynamics in the Douglasfir region of western Oregon and Washington. Natural Areas Journal, 8 , 190-201.

Thomas, J. W. (ed.) (1979). Wildlife habitats in managed forests-the Blue Mountains of Oregon and Washington. USDA For. Serv. Agric. Hdbk. No. 53. Portland, Oregon.

Yahner, R. H. (1988). Changes in wildlife communities near edges. Conserv. Biol., 2, $333-9$. 